\title{
RNA polymerase II subunit RPB9 is required for accurate start site selection
}

\author{
Melissa W. Hull, Keith McKune, and Nancy A. Woychik ${ }^{1}$ \\ Roche Institute of Molecular Biology, Nutley, New Jersey 07110 USA
}

The diverse functions of Saccharomyces cerevisiae RNA polymerase II are partitioned among its 12 subunits, designated RPB1-RPB12. Although multiple functions have been assigned to the three largest subunits, RPB1, RPB2, and RPB3, the functions of the remaining smaller subunits are unknown. We have determined the function of one of the smaller subunits, RPB9, by demonstrating that it is necessary for accurate start site selection. Transcription in the absence of RPB9 initiates farther upstream at new and previously minor start sites both at the CYC1 promoter in vitro and at the CYC1, ADH1, HIS4, H2B-1, and RPB6 promoters in vivo. Immunoprecipitation of RNA polymerase II from cells lacking the RPB9 gene revealed that all of the remaining 11 subunits are assembled into the enzyme, suggesting that the start site defect is attributable solely to the absence of RPB9. In support of this hypothesis, we have shown that addition of wild-type recombinant RPB9 completely corrects for the start site defect seen in vitro. A mutated recombinant RPB9 protein, with an alteration in a metal-binding domain required for high temperature growth and accurate start site selection in vivo, was at least 10 -fold less effective at correcting the start site defect in vitro. RPB9 appears to play a unique role in transcription initiation, as the defects revealed in its absence are distinct from those seen with mutants in RNA polymerase subunit RPB1 and factor e (TFIIB), two other yeast proteins also involved in start site selection.

[Key Words: Saccharomyces cerevisiae; mRNA initiation; TATA element]

Received August 9, 1994; revised version accepted January 20, 1995.

The eukaryotic multisubunit enzyme RNA polymerase II plays a major role in transcription because it mediates the synthesis of mRNA in response to signals transmitted by multiple transcription factors. Much effort has been directed toward an understanding of transcriptional regulation, as modulation of transcription levels in response to intra- or extracellular signals is an integral part of normal and diseased cell growth and development. Despite the fundamental role of RNA polymerase II in initiation, elongation, and termination of mRNA transcription, little is known about the specific functions of individual subunits, associations between subunits, or possible contacts between subunits and transcription factors.

Saccharomyces cerevisiae RNA polymerase II is relatively well defined as its 12 subunit genes, $R P B 1-R P B 12$, have been cloned and characterized (for review, see Young 1991; Woychik and Young 1994). The majority of the molecular mass of the enzyme consists of the two largest subunits, RPB1 and RPB2. These two subunits are homologous to the $\beta^{\prime}$ (Allison et al. 1985) and $\beta$ (Sweetser et al. 1987) subunits of Escherichia coli RNA polymerase and are thought to possess similar functions. Like $\beta^{\prime}$, RPB1 appears to be involved in DNA binding, and both $\beta$ and RPB2 appear to be involved in RNA ca-

${ }^{1}$ Corresponding author. talysis (Young 1991). RPB3 has some sequence similarity to the $E$. coli $\alpha$ subunit and, like $\alpha$, appears to play a role in subunit assembly (Kolodziej and Young 1989, 199lb). The remaining nine subunits, RPB4-RPB12, have no clear counterparts in prokaryotes, and their sequences have not revealed any further clues to their function.

We are interested in determining the functions of RPB4-RPB 12 because they probably have roles unique to the eukaryotic transcriptional apparatus. They also play critical roles in transcription, as most are essential for cell viability (Young 1991), are evolutionary well conserved (Woychik and Young 1994), and, in some cases, can be functionally replaced by their human counterparts (McKune and Woychik 1994). Of the nine small subunits, five of them, RPB5, RPB6, RPB8, RPB10, and $\mathrm{RPB} 12(\mathrm{~A} 10 \alpha)$, are assembled into all three eukaryotic RNA polymerases (Woychik et al. 1990; Treich et al. 1992). The remaining four subunits, RPB4, RPB7, RPB9, and $\mathrm{RPB} 11$, are uniquely represented in RNA polymerase II. Three of these, RPB7, RPB9, and RPB11, have sequence similarity to subunits in the other classes of yeast RNA polymerase: RPB7 is related to the C25 subunit of RNA polymerase III (Sadhale and Woychik 1994); RPB9 is related to the A12.2 subunit of RNA polymerase I (Nogi et al. 1993); and RPB11 is related to the AC19 subunit present in both RNA polymerase I and III (Woychik et al. 1993). 
Hull et al.

Although purified RNA polymerase II is capable of nonspecific initiation in vitro, specific initiation at eukaryotic promoters in vitro requires additional transcription factors (for review, see Conaway and Conaway 1993; Buratowski 1994b). Positioning of the initiation complex formed by RNA polymerase II and its associated basal transcription factors at precise regions of eukaryotic promoters determines the sites at which initiation of mRNA synthesis occurs. In general, the first step in the in vitro assembly of the basal transcription initiation complex at the promoters of higher eukaryotes /Conaway and Conaway 1993; Buratowski 1994b) is the binding of the TATA-binding protein (TBP) and its associated factors (the TFIID complex) to the TATA element. After TBP binding to the promoter, TFIIB, RNA polymerase II, and TFIF are then brought into the complex. Although TFIIE and TFIIH are subsequently recruited into the transcription initiation complex, RNA polymerase II, TFIID, TFIIB, and, in some cases, TFIIF have been shown to be sufficient for transcription initiation under certain conditions (Parvin and Sharp 1993; Tyree et al. 1993). Purified factors analogous to TFIIB, TFIIE, TFIIF, and TFIIH have been isolated in $S$. cerevisiae and are called factor e, factor $a$, factor $g$, and factor $b$, respectively /Gileadi et al. 1992; Henry et al. 1992; Sayre et al. 1992a; Tschochner et al. 1992). These four purified factors plus $S$. cerevisiae recombinant TFIID and purified RNA polymerase II support basal transcription in vitro (Sayre et al. 1992b).

Transcription initiation occurs at different distances downstream of the TATA box in higher eukaryotes, Schizosaccharomyces pombe and S. cerevisiae. In higher eukaryotes and $S$. pombe, transcription typically begins at a single site $\sim 30 \mathrm{bp}$ downstream of the TATA element (Corden et al. 1980; Benoist and Chambon 1981; Breathnach and Chambon 1981), whereas initiation in S. cerevisiae begins at multiple sites $\sim 40-120$ bp downstream of the TATA element (Guarente 1987, 1988; Struhl 1987, 1989|. The position of the initiation sites recognized by the $S$. cerevisiae initiation complex has been shown to be entirely dependent on functions possessed by the initiation transcription factor e the functional homolog human TFIIB (Tschochner et al. 1992)] and RNA polymerase II ( $\mathrm{Li}$ et al. 1994). Thus, whereas TBP directs the placement of the initiation complex by binding DNA, RNA polymerase II and factor e (TFIIB) determine how far downstream of the TATA box transcription is initiated. The specific subunits of RNA polymerase II involved in this process and how they interact with other components such as TFIIB have yet to be determined.

We decided to examine the effects of RPB9 on transcription in vitro and in vivo. Cells that have the $R P B 9$ gene deleted are viable but cold and temperature sensitive (Woychik et al. 1991). Upon examination of the consequences of deletion of $R P B 9$ on transcription in vitro, we found that the start site selection pattern was altered, even though nearly normal levels of basal and activated transcripts were obtained; similar alterations in transcription initiation patterns are also seen in vivo. Addition of recombinant RPB9 to the deletion strain extract restores normal transcription initiation site selection in vitro. Thus, we have demonstrated that the $S$. cerevisiae RNA polymerase II subunit RPB9 is a component of the initiation complex required for accurate start site selection.

\section{Results}

$R P B 9$ has evolutionary conserved zinc-binding domains

The 14-kD RNA polymerase II subunit RPB9 is evolutionary conserved, with counterparts identified in humans (hRPB14.5) (Acker et al. 1993), Drosophila (RPII15) (Harrison et al. 1992), and plants (Fig. 1). RPB9 is also related to the $S$. cerevisiae RNA polymerase I subunit A12.2 (Nogi et al. 1993) and has a homolog in archaebacteria. We discovered the relatedness of RPB9 to its archaebacterial Thermococcus celer (accession no. L27650)
Figure 1. RPB9 architecture is highly conserved. (A) Schematic representation of conserved regions among RPB9 homologs. Solid areas represent regions of high amino acid conservation within metal-binding regions; dotted regions represent regions of high amino acid conservation outside of the metal-binding domains. $(B)$ Identical amino acids are boxed and in bold; conserved residues are boxed. Only identities in the putative metal-binding regions are noted between the $T$. celer homolog and the other RPB9 counterparts.

A

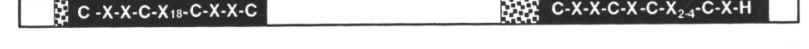

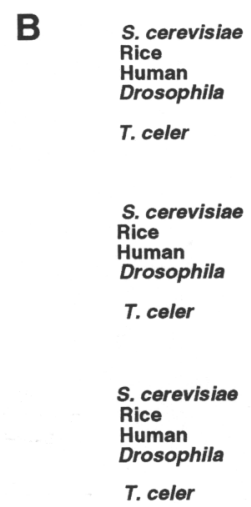
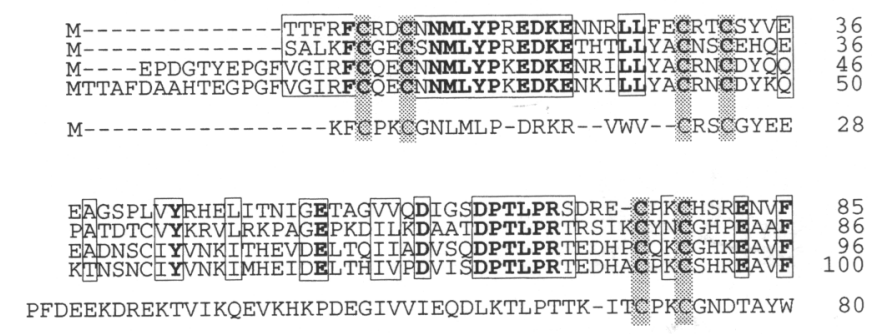
and plant (rice, accession no. D23155) counterparts using TFASTA (Genetics Computer Group, Inc., Madison, WI) and BLAST (NCBI) data base searches against yeast RPB9. The most striking conservation between RPB9 and its relatives is outlined by the two metal binding domains that span most of the relatively small polypeptide. Although both the yeast RPB9 and its human homolog, as well as the A12.2 subunit, are known to have zinc-binding activity (Carles et al. 1991; Treich et al. 1991; Acker et al. 1993) it is not known whether these domains are important for DNA binding or protein-protein interaction. In addition to the conserved cysteines within the zinc-binding domains, there are two additional regions of identity between RPB9 and the RNA polymerase II subunits from other species; one within the first zinc-binding domain; and the other just before the second zinc-binding domain. Loss of the Drosophila RPII15 gene results in lethality (Harrison et al. 1992), while the $S$. cerevisiae $R P B 9$ gene is only required for growth at high and low temperatures, suggesting that the RPB9 counterparts in other higher eukaryotes may also have essential roles.

WY9 nuclear extracts support basal and activated transcription but are defective in $m R N A$ start site selection

Of the 12 yeast RNA polymerase II subunits, 2, RPB4 and RPB9, are not essential for viability. Deletion of either of these genes only results in slower growth at moderate temperatures, although deletion is lethal at high or low temperatures. Previously, in vitro transcription using nuclear extracts prepared from cells lacking the $R P B 4$ gene showed only negligible levels of basal transcription and greatly reduced levels of activated transcription (Edwards et al. 1991). This in vitro transcriptional defect represents the effects of the loss of function of RPB4 and $\mathrm{RPB} 7$, as RPB7 no longer purifies with RNA polymerase II when RPB4 is absent. It is still not clear what effects deletion of RPB4 has on basal and activated transcription in vivo.

We are interested in understanding the role of RPB9 in transcription. To this end we made use of the conditional S. cerevisiae mutant strain that lacks the $R P B 9$ gene, designated WY9, to determine whether RPB9 was required for in vitro transcription and to study the consequences of its absence on transcription initiation. In vitro transcription at the $C Y C 1$ promoter using nuclear extracts from WY9 cells revealed that the basal and activated levels of transcription with mutant WY9 extracts were comparable to those seen with wild-type extracts (Fig. 2). Therefore, unlike the other nonessential subunit RPB4, loss of RPB9 does not drastically decrease the level of transcription in vitro. RPB9 also does not affect activation by GAL4-VP16.

Although the absolute levels of in vitro transcription were not significantly lower, the mutant extracts consistently produced aberrant transcript lengths. WY9 extracts directed the synthesis of a greater percentage of longer transcripts compared with wild-type extracts.
A

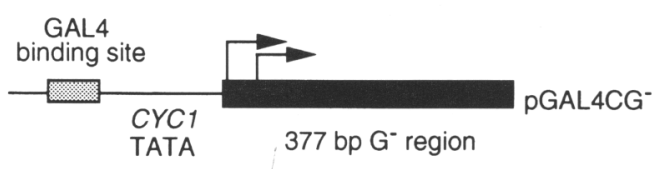

B

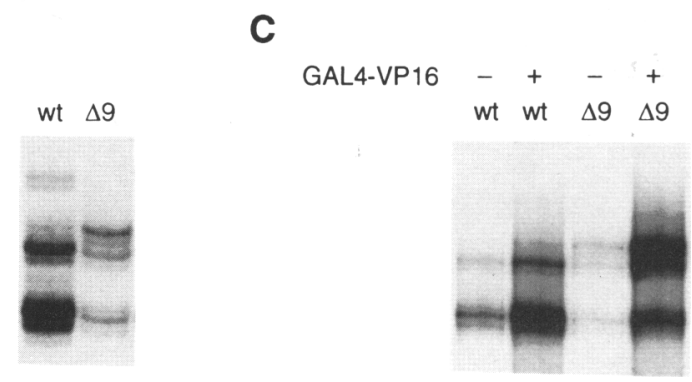

Figure 2. Loss of the $R P B 9$ gene alters the start site selection for both basal and activated transcripts synthesized in vitro. $|A|$ The template plasmid used for the transcription reactions, pGAL4CG', contains a single GAL4-binding site and a $C Y C 1$ TATA element controlling the expression of G-less transcripts. The two predominant transcripts are $\sim 350$ and 370 nucleotides. $(B)$ In vitro transcription products obtained from both wild-type $\mathrm{N} 222$ (wt) and $R P B 9$ deletion $(\Delta 9$ ) strain extracts using $60 \mathrm{mg}$ of extract and $200 \mathrm{ng}$ of template. $(C)$ Deletion of $R P B 9$ does not affect activation by GAL4-VP16 in vitro. GAL4-VP16 (150 mM) was added to in vitro transcription reactions from both the wildtype N222 or WY9 strain extracts. Sixty milligrams of extract and $200 \mathrm{ng}$ of template were used in each reaction.

This defect was not influenced by activation, as comparable transcript patterns were obtained after basal or activated transcription. The alteration in the characteristic transcript profile in WY9 cells suggested that RPB9 influences mRNA start site selection at the CYC1 promoter in vitro.

\section{WY9 nuclear extracts are temperature sensitive}

In addition to having alterations in start site selection, in vitro transcription with WY9 extracts was also more sensitive to heat inactivation than wild-type extracts. This defect was demonstrated using two different approaches. First, wild-type or WY9 extracts were incubated with pGAL4CG ${ }^{-}$template for $0,10,25,50$, or $120 \mathrm{~min}$ at $42^{\circ} \mathrm{C}$. The mixture was then cooled, nucleotides were added, and the transcription reaction was continued at the permissive temperature of $23^{\circ} \mathrm{C}$. Although the transcriptional activity of both wild-type and WY9 extracts decreased after preincubation at $42^{\circ} \mathrm{C}$ for 10 and $25 \mathrm{~min}$, the activity of the WY9 extract was more sensitive to heat inactivation (Fig. 3). After pretreatment at $42^{\circ} \mathrm{C}$ for 10 min, the WY9 extract had $9 \%$ activity, whereas the wild-type extract had $37 \%$ activity relative to the unheated extract. Preincubation for 25 min produced $2 \%$ and $10 \%$ activity for WY9 and wild-type extracts, respectively. Wild-type and mutant extracts preheated at $42^{\circ} \mathrm{C}$ for 50 or $120 \mathrm{~min}$ had no detectable transcriptional activity at 23 or $30^{\circ} \mathrm{C}$.

In the second approach, instead of preincubation of the 
Hull et al.

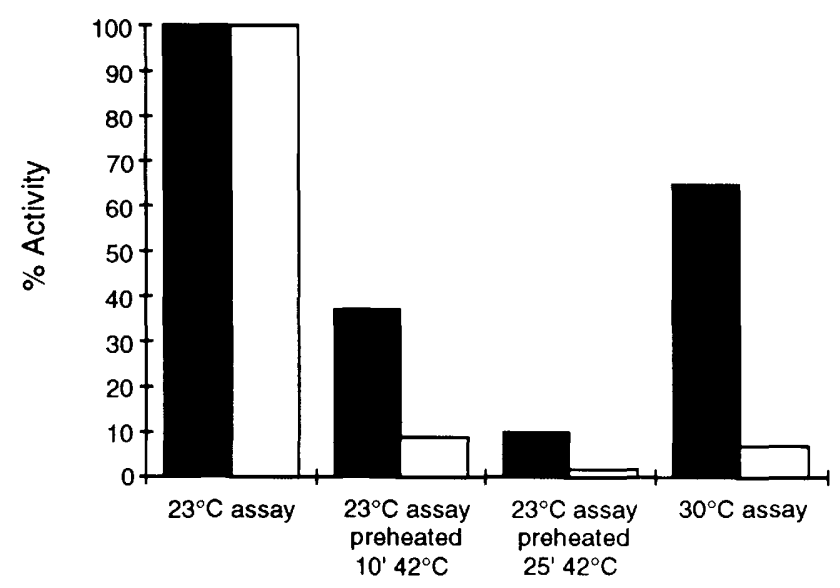

Figure 3. In vitro transcription activity of WY9 extract is more susceptible to heat inactivation than wild-type extracts. Transcription reactions were performed with wild-type $\mathrm{N} 222(\mathbf{\square})$ and WY9 (口) strain extracts at the permissive temperature of $23^{\circ} \mathrm{C}$, the semipermissive temperature of $30^{\circ} \mathrm{C}$, or at $23^{\circ} \mathrm{C}$ after pretreatment of the extracts at $42^{\circ} \mathrm{C}$. The transcriptional activity obtained is expressed as a percentage of the activity of the same extract at the permissive temperature.

extract at elevated temperatures prior to transcription, the entire reaction was done at higher than normal temperatures. In vitro transcription was performed at the usual $23^{\circ} \mathrm{C}$ as well as at $30^{\circ} \mathrm{C}$ and $37^{\circ} \mathrm{C}$. Although no activity was obtained from either extract at $37^{\circ} \mathrm{C}$, in the $30^{\circ} \mathrm{C}$ assay the WY9 extract had only $7 \%$ activity while the wild type extract had $65 \%$ activity relative to the comparable reactions at $23^{\circ} \mathrm{C}$ (Fig. 3). Both of these experiments demonstrated that the basal transcriptional activity of the mutant was temperature sensitive relative to the isogenic wild-type extract, consistent with its temperature-sensitive phenotype in vivo.

\section{RNA polymerase II from WY9 cells lacks only RPB9}

We wanted to test whether the RNA polymerase II in WY9 cells lacked other subunits in addition to RPB9. Removal of a single subunit in a multisubunit complex could have drastic effects on the overall structure, function, and assembly of the complex. Loss of additional subunits may occur if the absent subunit normally functions as a link to the rest of the enzyme. This was observed for RPB4, where deletion of its gene also results in the loss of assembly of RPB7 with RNA polymerase II.

We immunoprecipitated RNA polymerase II from WY9 and wild-type cells with an antibody to the RPB 1 carboxy-terminal domain (Thompson et al. 1990; Kolodziej and Young 1991a) to observe which subunits were able to assemble into a stable complex in the absence of RPB9. WY9 RNA polymerase II lacked only RPB9, as the RPB1 subunit assembled with all of the remaining 10 subunits (Fig. 4). This result indicates that the in vitro transcription defect in start site selection is attributable to the loss of the RPB9 subunit.

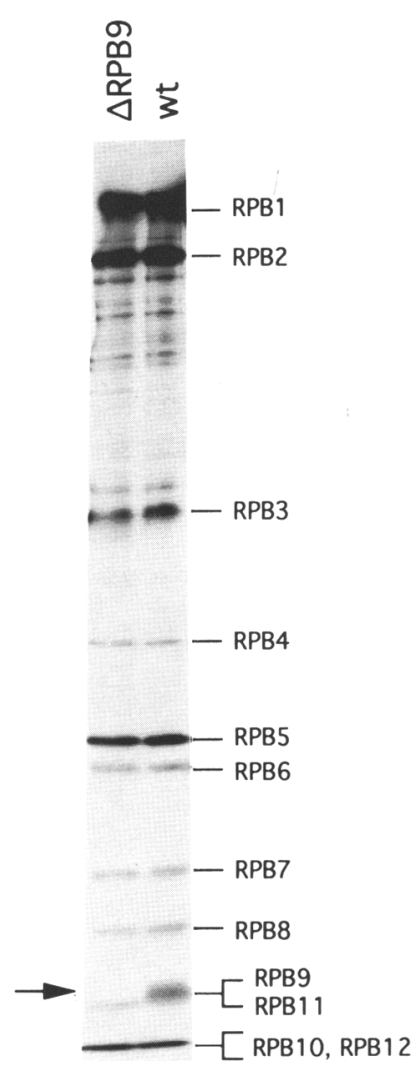

Figure 4. RNA polymerase II immunoprecipitated from WY9 lacks only the RPB9 subunit. RNA polymerase was immuno-

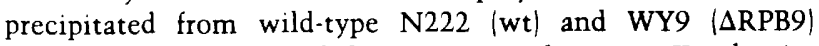
strains. The positions of the 12 RNA polymerase II subunits (RPB1-RPB12) are indicated. The arrow indicates the absence of $\mathrm{RPB} 9$ in WY9 RNA polymerase II.

\section{Recombinant RPB9 corrects the start site defect in vitro}

Because RNA polymerase II in WY9 cells was missing only RPB9, we tested whether addition of purified RPB9 corrected the transcriptional defect at the CYC1 promoter in vitro (Fig. 5). A range of concentrations from 1 to $70 \mathrm{ng}$ of purified glutathione $S$-transferase (GST)-

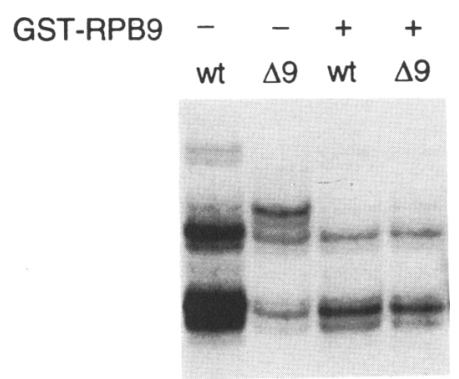

Figure 5. RPB9 is required for accurate start site selection in vitro. Seventy nanograms of recombinant GST-RPB9 was added, as indicated, to in vitro transcription reactions per-

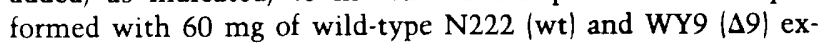
tracts and $200 \mathrm{ng}$ of template. 
RPB9 was added to the WY9 and wild-type transcription reactions. Remarkably, as little as $1 \mathrm{ng}$ ( 25 fmoles) of GST-RPB9 restored normal transcription initiation. The GST control had no effect on transcription at the same range of concentrations. Therefore, we concluded that RPB9 is necessary for accurate start site selection in this assay.

\section{$R P B 9$ is essential for start site selection in vivo}

Transcript mapping using primer extension assays on poly $(\mathrm{A})^{+}$RNA prepared from the WY9 deletion and wild-type cells corroborated the in vitro results and revealed that RPB9 also influences transcription start site selectivity for multiple genes in vivo. In addition to $C Y C 1$, four other genes, ADH1, HIS4, H2B-1, and RPB6, had comparable alterations in the size and quantity of mRNA transcripts in WY9 cells relative to the wild-type transcript population (Fig. 6). Each of these genes had transcripts with one or more new, longer upstream start sites as well as a general increase in the abundance of transcripts representing previously minor upstream start sites in WY9 compared with wild-type cells. In addition, the relative amounts of transcripts representing minor downstream start sites in the ADH1, HIS4, and H2B-1 genes was lower in WY9 cells. The transcript profiles for two genes, SPT15 (Fig. 6) and HIS3 (not shown), were identical in WY9 and wild-type cells. Taken together, these results demonstrate that RPB9 is essential for accurate initiation of multiple genes in vivo.

\section{$R P B 9$ metal-binding domains are important for function in vivo and in vitro}

Deletion of $R P B 9$ in $S$. cerevisiae cells results in temperature sensitivity at $37^{\circ} \mathrm{C}$ (Woychik et al. 1991). Because RPB9 influences start site selection and contains two conserved zinc fingers, we wanted to determine whether the zinc fingers are required for RPB9 function. We mutated the codon of the first cysteine in the first zinc finger to encode an alanine residue and tested the effect of this C7A mutation in vitro and in vivo. Previous studies on other zinc-binding domains have demonstrated that mutation of only one of the four cysteine residues effectively disnupts zinc finger function (Blumberg et al. 1987; Johnston 1987; Johnston and Dover 1987).

We first tested whether the C7A mutant complemented the WY9 temperature-sensitive growth phenotype in vivo. Although a wild-type $R P B 9$ plasmid transformed into WY9 supports growth at high temperature,

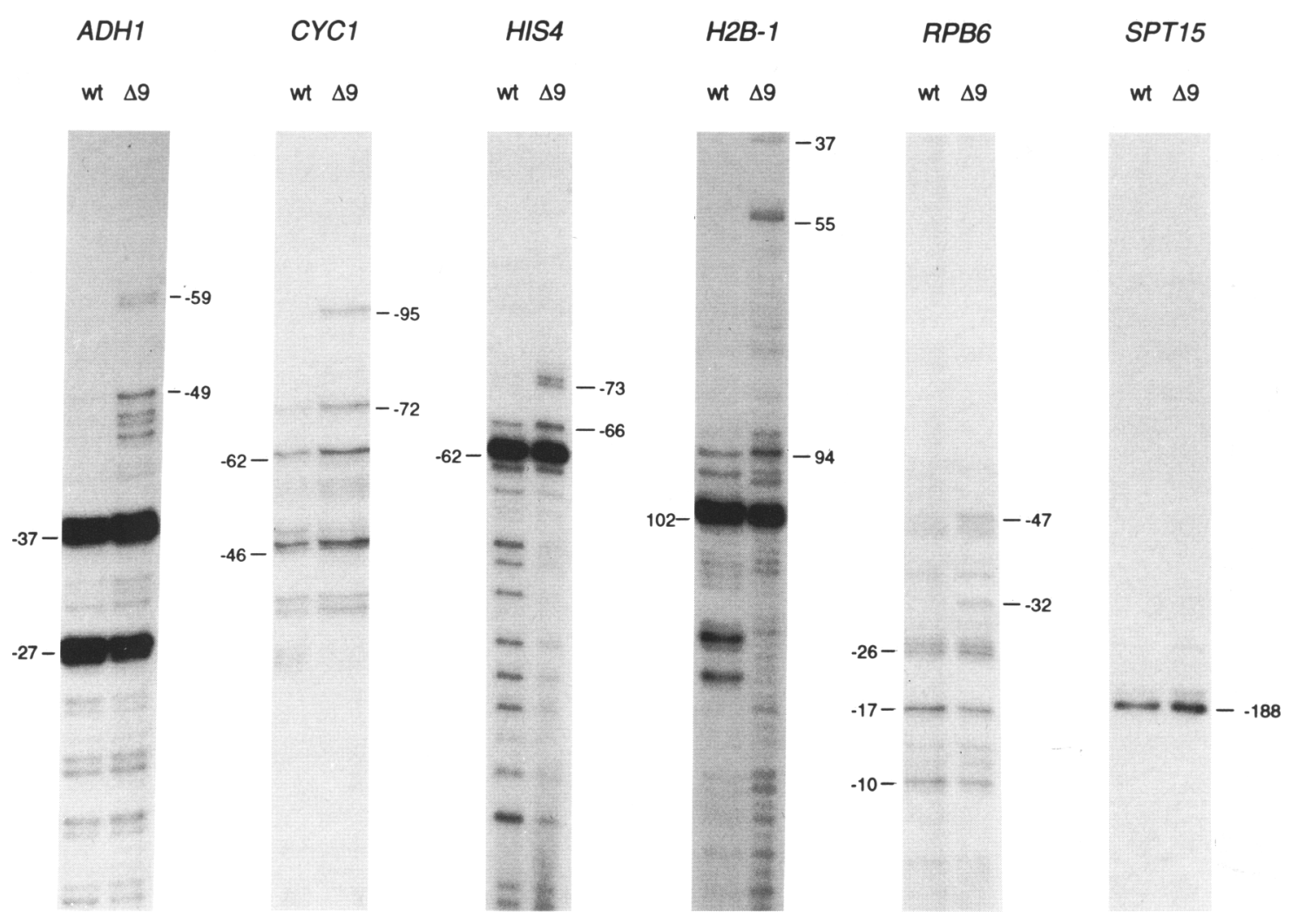

Figure 6. RPB9 is required for accurate start site selection of multiple genes in vivo. The start sites shown for the wild-type N222 (wt) and WY9 $(\Delta 9)$ strains reflect the number of base pairs from the ATG translational start codon except in the case of $H 2 B-1$, in which the numbers represent number of base pairs from the TATA element. Although primer extension of SPT15 by Berroteran et al. (1994) produced two bands, our experiments produced only one band, consistent with nuclease S1 analysis (Schmidt et al. 1989), which revealed a single major start site for this gene. 
Hull et al.

the C7A mutant did not complement WY9 temperature sensitivity (Fig. 7A). Primer extension analysis at the $A D H 1$ promoter with mRNA prepared from RPB9|C7A) cells revealed that the point mutation resulted in start site defects identical to those seen in cells completely lacking the RPB9 subunit shown (data not shown). These results demonstrate the $\boldsymbol{c}^{*}$ the zinc fingers are critical for RPB9 function in vivo because disruption of their structure alters start site selection and abolishes yeast cell growth at high temperature.

Because loss of RPB9 shifts mRNA start sites upstream and recombinant RPB9 can correct this defect in vitro, we tested whether the $\mathrm{C} 7 \mathrm{~A}$ mutation now fails to compensate for the start site defect. Addition of various concentrations of GST-RPB9(C7A) to the transcription reactions revealed that the mutant subunit can still function, but much less efficiently than the wild-type RPB9 (Fig 7B). Nearly 10 times more $(9 \mathrm{ng}$ ) mutant GSTRPB9(C7A), compared with 1 ng used for the wild-type GST-RPB9, was needed to correct the start site defect.

We also tested whether the Drosophila homolog of RPB9, RPII15, could complement the temperature-sensitive phenotype resulting from the loss of $S$. cerevisiae RPB9. Like RPB9, RPII15 has two zinc-binding domains (Fig. 1) and $77 \%$ of its amino acid sequence is conserved with S. cerevisiae RPB9 (Woychik et al. 1991). The $R P I I 15$ BamHI gene cassette gene was placed under control of the yeast $R P B 9$ promoter and transformed into WY9 cells. Expression of RPII15 did not complement the conditional phenotype, whereas the yeast control plasmid containing an RPB9 BamHI cassette did complement the growth phenotype. These results suggest that while the zinc-binding domain is critical for RPB9 function in vivo, it is not the only part of the protein important for its function as the Drosophila counterpart does not function in yeast.

$R P B 9(C 7 A)$ and dmRPB9 assemble with $R N A$ polymerase II

To establish that the RPB9 point mutant and dmRPB9 are expressed and stable in yeast cells, we immunoprecipitated RNA polymerase II from mutant RPB9C(7)A and dmRPB9 cells (Fig. 8). The radioactively labeled $\mathrm{RPB} 9 / 11$ subunits run as a relatively intense, thick band that can sometimes be resolved into a doublet. In the absence of RPB9, a faint, thin band representing only $\mathrm{RPB} 11$ is visible upon SDS-PAGE. Immunoprecipitation of RNA polymerase II from RPB9(C7A) yeast cells revealed that the mutant subunit assembles with the enzyme, revealed by a thick band in this region representing the RPB9(C7A)/RPB11 doublet (Fig. 8). However, it appears that the RPB9(C7A) subunit does not assemble as efficiently with the enzyme since the relative intensity of this subunit band is lower than that of the RPB9 band immunoprecipitated from wild type cells. The 15$\mathrm{kD}$ dmRPB9 subunit also assembles with the enzyme and consistently runs as a broad, diffuse band above RPB 11 .

Because the RPB9(C7A) mutant assembles with RNA polymerase II, the start site defect observed is unlikely to result from a major conformational change in RNA polymerase II resulting from the loss of the RPB9 subunit. This result also corroborates our in vitro reconstitution experiments using mutant and wild-type recombinant RPB9, strongly supporting a direct and specific role for RPB9 in determination of accurate start site selection.

\section{Discussion}

Transcription initiation is a crucial regulatory step in eukaryotic gene expression. Accurate transcription initiation is a result of complex interactions between multiple components of the transcription machinery. In particular, binding of TBP to the TATA box helps to position RNA polymerase II and TFIIB. In turn, RNA polymerase II and TFIIB position the transcription start sites of different genes at fixed distances downstream of the TATA box. We have shown that RPB9 is involved in positioning the transcription initiation site. The involvement of RPB9 in start site selection is consistent with the biochemical data implicating RNA polymerase II and TFIIB in positioning the start
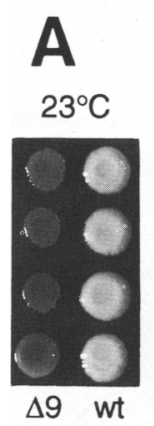

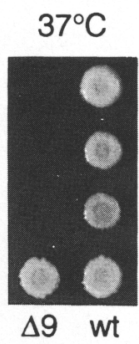

plac195

dmRPB9

RPB9(C7A)

RPB9

Figure 7. An RPB9 zinc finger mutant and the RPB9 D. melanogaster homolog do not complement the WY9 temperature-sensitive defect in vivo or in vitro. $(A)$ Wild-type $(w t)$ and WY $(\Delta 9)$ strains transformed with the indicated plasmids were tested for their ability to grow on YPD medium at temperatures indicated. (B) Increasing amounts of purified GST, GST-RPB9, or GST-RPB9(C7A) protein, represented by the open wedge, were added to in vitro transcription reactions with $80 \mathrm{ng}$ of wild-type N222 (WT) or WY9 ( $\Delta 9$ ) extracts and $300 \mathrm{ng}$ of template. 


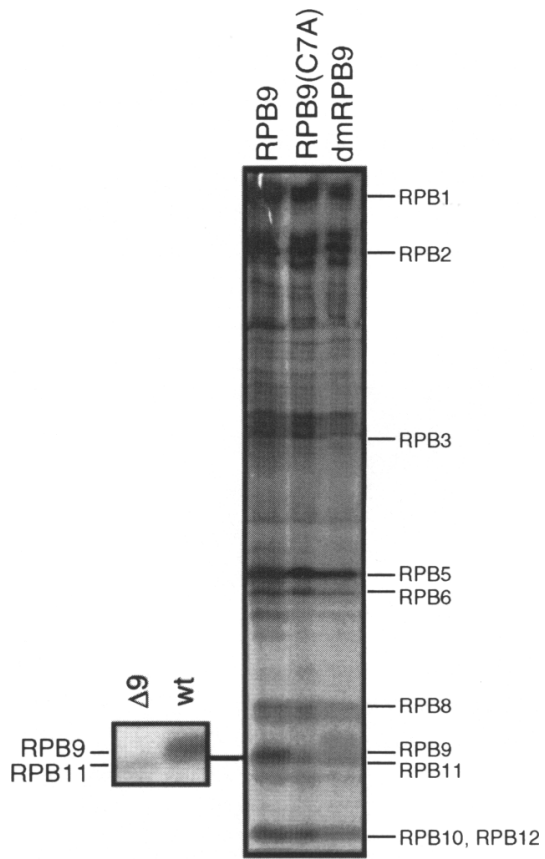

Figure 8. $\mathrm{RPB} 9(\mathrm{C} 7 \mathrm{~A})$ and dmRPB9 assemble with RNA polymerase II. RNA polymerase II was immunoprecipitated from wild-type N222 (RPB9), mutant RPB9|C7A) and dmRPB9 yeast cells. The positions of RNA polymerase II subunits (RPB1$\mathrm{RPB} 12$ ) are indicated. The small box at left compares the close migrating RPB9/RPB11 doublet present in wild-type cells (wt) to the single, sharp RPB11 band present in $\Delta 9$ cells $(\Delta 9)$. The RPB4 and RPB7 subunits are present at substoichiometric levels and are not detectable in either wild-type or mutant extracts in this experiment.

site relative to the TATA box ( $\mathrm{Li}$ et al. 1994). It is further supported by genetic data implicating RPB1, RPB2, RPB9, and TFIIB in start site selection in S. cerevisiae.

Various genetic approaches have been employed in $S$. cerevisiae to identify mutants with altered transcription. SPT genes were identified as suppressors of the Ty or $\delta$ insertions in a $5^{\prime}$-noncoding region of a gene (Winston
1992). The spt mutant screen appears to have targeted genes that affect TATA box selection, as some spt suppressors initiate at a TATA box downstream from the presumably "stronger" TATA box contained within the Ty or $\delta$ element. The SPT genes isolated can be placed into two groups, TBP-related and histone-related. The wide variety of genes isolated as SPT mutants underscores the complexity of the interactions that result in accurate transcription initiation. Although no RNA polymerase II subunit genes have yet been identified through $S P T$ screens, a directed screen $S P T$-like screen with mutagenized RPB1 and RPB2 revealed that certain mutations in these two subunits suppress $\delta$ insertion mutations. However, the overall transcriptional defects seen with these mutations are very weak (Hekmatpanah and Young 1991).

Two other genetic approaches have been devised that appear to have, in some cases, selected for mutants that use the same TATA box but have altered transcription initiation sites relative to the TATA. One approach implemented a selection for mutants that initiated farther downstream than normal, thereby bypassing an aberrant translation initiation codon. In agreement with the biochemical data, which implicate TFIIB and RNA polymerase II in the positioning of the transcription initiation sites relative to the TATA box (Li et al. 1994), two genes isolated by this screen influence start site selection. These genes, designated SUA7 and SUA8, encode transcription factor $\mathrm{e}$ (TFIIB) and RPB1, respectively (Pinto et al. 1992; Berroteran et al. 1994). Another related genetic approach, involved a selection for mutants that initiated farther upstream than normal. This screen identified a mutant gene, called $S H I$, that alters start site selection at two promoters in a manner similar to the RPB981::HIS3 mutation in WY9 cells (Furter-Graves et al. 1991). Although the cloning of the $S H I$ gene has not been published, a personal communication mentioned in a recent review revealed that $S H I$ and $R P B 9$ represent the same gene (Buratowski 1994a).

The start site phenotypes observed with SUA7 and SUA8 mutants are distinct from those observed for the RPB981::HIS3 mutant (Table 1), suggesting that RPB9 plays a unique role that is complementary to the func-

Table 1. In vivo transcription initiation defects in start site selection mutants

\begin{tabular}{|c|c|c|c|c|c|}
\hline & $R P B 9 \Delta 1:: H I S 3$ & SHI & sua $8-1$, sua $8-3$ & sua $7-1$ & $r p b 1-501, r p b 1-502$ \\
\hline$A D H 1$ & $\Leftarrow$ & $\Leftarrow$ & $\Rightarrow$ & $\Rightarrow$ & N.D. \\
\hline CYC7 & N.D. & N.D. & $\Rightarrow$ & $\Rightarrow$ & N.D. \\
\hline HIS4 & $\Leftarrow$ & N.D. & $\Rightarrow$ & no change & $\Leftarrow$ \\
\hline HIS3 & no change & N.D. & no change & no change & N.D. \\
\hline SPT15 & no change & N.D. & no change & no change & N.D. \\
\hline CYC1 & $\Leftarrow$ & N.D. & N.D. & $\Rightarrow$ & N.D. \\
\hline$H 2 B-1$ & $\Leftarrow$ & $\Leftarrow$ & N.D. & N.D. & N.D. \\
\hline$R P B 6$ & $\Leftarrow$ & N.D. & N.D. & N.D. & N.D. \\
\hline
\end{tabular}

The arrows indicate that the new start sites seen in the mutant strain are upstream (arrow pointing left) or downstream (arrow pointing right) of major start sites obtained with the corresponding isogenic wild-type strain. (N.D.) Not determined. Data from RPB1, SUA8, SUA7, and SHI mutants were adapted from Hekmatpanah and Young (1991), Berroteran et al. (1994), Pinto et al. (1992), and FurterGraves et al. (1991). 
tions of RPB1 and factor e. SUA7 or SUA8 mutants typically shift initiation downstream of normal, to sites that were minor in wild-type cells (Pinto et al. 1992; Berroteran et al. 1994), whereas RPB $\delta 1:: H I S 3$ cells shift initiation upstream of normal, sometimes to new sites. Therefore, whereas factor e and RPBl confer start site selectivity from a fixed array of normally utilized sites, RPB9 is required for specificity, that is, recognition of correct mRNA initiation sites from those not normally utilized. However, as with the RPB $981:: H I S 3$ mutant, initiation at HIS3 and SPT15 promoters was also unaffected in both SUA7 and SUA8 mutants. Therefore, it appears that some genes are immune to perturbation by mutants in RPBI, RPB9, or factor e.

We now know of five proteins, TBP, RPB9, factor e (TFIIB), RPB1, and RPB2, that influence start site selection. The involvement of RPB1 and RPB2 is not unexpected because together they constitute two-thirds of the molecular mass of the enzyme and, thus, many of its essential functions. RPB1 is also thought to bind DNA, and RPB2 appears to carry the catalytic site for mRNA synthesis (Young 1991). The involvement of RPB9 was unanticipated but intriguing in light of its overall structure, in which half of its 122 amino acids form two zinc finger domains spanning the length of the protein. RPB9 may bind DNA and contribute to start site specificity through its interaction with DNA and/or other components of the initiation complex. Future experiments will now help establish how these components interact and which interactions are critical for accurate transcription initiation.

\section{Materials and methods}

Yeast strains and plasmids

The RPB9 deletion strain WY9 (MATa ura3-52 his38200 leu2-3 leu2-112 lys28201 ade2 RPB981::HIS3) and isogenic parent N222 (MAT $\alpha$ ura3-52 his38200 leu2-3 leu2-112 lys28201 ade2) were used to prepare nuclear extracts for in vitro transcription experiments. The URA3/2- $\mu \mathrm{m}$ plasmid plac195 /Gietz and Sugino 1988) was transformed into WY9 and N222 to generate WY79 and WY80, respectively. pRP951 is a plac195 derivative carrying a PCR-generated fragment of the $R P B 9$ gene, which has $\sim 260$ bp of $5^{\prime}$ and $\sim 60$ bp of $3^{\prime}$-flanking sequences. pRP951 also has a BamHI site at each end of the RPB9 protein-coding region to facilitate substitution with RPB9 mutants and homologs. pRP951 was transformed into WY9 and N222 to create WY81 and WY82, respectively. pRP952 has the same $R P B 9$ fragment as pRP951, except that the first cysteine (TGC, corresponding to amino acid 7) of the first zinc-binding domain of RPB9 was changed to an alanine (GCC) using PCR (Ho et al. 1989). pRP952 was transformed into WY9 and N222 to generate WY83 and WY84, respectively. pRP953 is another plac195 derivative with a PCR-generated insert in which the $\sim 260 \mathrm{bp}$ of $5^{\prime}$ and $\sim 60 \mathrm{bp}$ of $3^{\prime}$ RPB9-flanking DNA surrounds the coding region of the Drosophila melanogaster RPB9 homolog (Harrison et al. 1992), RPII15. The RPII15 gene in pRP953 had BamHI ends created by PCR and was ligated into a BamHI site that replaced the deleted RPB9-coding region. pRP953 was transformed into WY9 and N222 to generate WY85 and WY86, respectively. The other plasmids in this study are described below. The accuracy of all PCR-synthesized genes was verified using sequence analysis.

\section{Immunoprecipitation of RNA polymerase II}

${ }^{35} \mathrm{~S} \mid$ methionine-labeled extracts were prepared from N222 and WY9 and immunoprecipitated with the RPB1 antibody directed against the carboxy-terminal domain (Thompson et al. 1990) as described by Kolodziej and Young (1991a). The immunoprecipitated RNA polymerase II was subjected to SDS-PAGE using a $12.5 \%$ low cross-linker formula (Dreyfuss et al. 1984).

\section{In vitro transcription assays}

Nuclear extracts were prepared from isogenic wild-type (N222) and RPB9 $1:: H I S 3$ (WY9) strains according to the method of Lue and Kornberg (Lue et al. 1991). In general, transcription reactions were performed at $23^{\circ} \mathrm{C}$ with $60-80 \mathrm{mg}$ of extract and 200-300 ng of pGAL4CG ${ }^{-}$template (Lue et al. 1989). Basal and activated transcriptional activity were assayed with $60 \mathrm{mg}$ of extract and $200 \mathrm{ng}$ of template. To examine transcriptional activation in the wild-type versus $R P B 9$ deletion background, GAL4-VP16 (a generous gift of Sha-Mei Liao) was added at the beginning of the transcription reactions to a final concentration of $150 \mathrm{nM}$ as described (Liao et al. 1991).

To test the effects of the GST, GST-RPB9, and GSTRPB9(C7A) fusion proteins on in vitro transcription, 1, 3, 9, or $27 \mathrm{ng}$ of each partially purified protein was added to reactions containing $60 \mathrm{mg}$ of extract and $300 \mathrm{ng}$ of pGAL4CG ${ }^{-}$template.

The effects of temperature on in vitro transcription activity were tested by either pretreating the WY9 and N222 extracts at a high temperature and shifting to the permissive temperature to complete the transcription reaction or by performing the transcription reaction at the higher temperature. Sixty milligrams of wild-type N222 (wild type) or WY9 (RPB9A1::HIS3) extracts and $300 \mathrm{ng}$ of pGAL4CG ${ }^{-}$template were incubated for $0,10,25,50$, or $120 \mathrm{~min}$ at $42^{\circ} \mathrm{C}$ in standard reaction buffer minus nucleotides (Liao et al. 1991). The mixture was then cooled to $4^{\circ} \mathrm{C}$, nucleotides were added, and the transcription reaction was continued at the permissive temperature of $23^{\circ} \mathrm{C}$. Alternatively, the entire transcription reaction was performed at either $23^{\circ} \mathrm{C}$ or $30^{\circ} \mathrm{C}$. Wild-type and mutant extracts preheated at $42^{\circ} \mathrm{C}$ for 50 or $120 \mathrm{~min}$ had no detectable transcriptional activity at $23^{\circ} \mathrm{C}$, whereas no detectable transcription activity was obtained from either the N222 or WY9 extracts at $37^{\circ} \mathrm{C}$. The level of transcriptional activity was measured by quantification of all CYC1 transcript bands using a Betascope 603 blot analyzer (Betagen).

\section{Preparation of GST fusion proteins}

pRP954 and pRP955 are pGEX-2T derivatives in which the wildtype and C7A mutant RPB9 protein-coding regions have replaced the EcoRI-BamHI fragment of the polylinker, respectively. The wild-type RPB9 protein-coding region was amplified by PCR of pRP951 DNA with the oligonucleotides $5^{\prime}$-CACGGATCCATGACTACGTTTAGATTTTGC-3' and 5'-ATGAATTCCTCATGAAAACTGCGTCCTTTTG- $3^{\prime}$. The mutant RPB9 protein-coding region was amplified by PCR of pRP952 with the same oligonucleotides. Expression of the fusion protein in DH5 $\alpha$ was induced for $2 \mathrm{hr}$ following the addition of 100 mM IPTG. GST-RPB9 was purified on glutathione-Sepharose 4B (Pharmacia) as suggested by the manufacturer.

\section{Primer extension analysis}

Primer extension analysis was performed using $5 \mu \mathrm{g}$ of poly $\mid \mathrm{A})^{+}$ RNA according to Williams and Mason (1985) after annealing at $50^{\circ} \mathrm{C}$ from $4-18 \mathrm{hr}$ to the following radioactively labeled oligo- 
nucleotides, $A D H 1$, 5'-AGAAGATAACACCTTTTTGAG-3' CYC1, 5'-TGTGGCATTGTAGACATCTAG-3' ${ }^{\prime} H 2 B-1,5^{\prime}$-CAGCTGGGGCTTTGGAGG-3', HIS4, 5'-CAGATCATCAATTAACGGTAG-3'; RPB6, 5'-CTCCTCATCAGAAAAATGCTCTAC-3'; SPT15, 5'-CTTTAAACGTTCCTCATCGG-3'. The primer extension reactions were run on $6 \%$ polyacrylamide sequencing gels.

\section{Acknowledgments}

We thank Sha-Mei Liao for kindly providing her expertise, pGALCG $^{-}$and GAL4-VP16 for in vitro transcription experiments, Aled Edwards for helpful discussions, Nancy Thompson for the RPB1-CTD antibody, David Kindelberger for technical assistance and advice, and Stephen Buratowski for comments on the manuscript.

The publication costs of this article were defrayed in part by payment of page charges. This article must therefore be hereby marked "advertisement" in accordance with 18 USC section 1734 solely to indicate this fact.

\section{Note added in proof}

A paper describing the cloning and characterization of the SHI gene was published while this manuscript was under review (Furter-Graves, E.M., B.D. Hall, and R. Furter. 1994. Role of a small RNA pol II subunit in TATA to transcription start site spacing. Nucleic Acids Res. 22: 4932-4936).

\section{References}

Acker, J., M. Wintzerith, M. Vigneron, and C. Kedinger. 1993. Structure of the gene encoding the $14.5 \mathrm{kDa}$ subunit of human RNA polymerase II. Nucleic Acids Res. 21: 5345-5350.

Allison, L.A., M. Moyle, M. Shales, and C.J. Ingles. 1985. Extensive homology among the largest subunits of eukaryotic and prokaryotic RNA polymerases. Cell 42: 599-610.

Benoist, C. and P. Chambon. 1981. In vivo sequence requirements of the SV40 early promotor region. Nature 290: 304 310.

Berroteran, R.W., D.E. Ware, and M. Hampsey. 1994. The sua8 suppressors of Saccharomyces cerevisiae encode replacements of conserved residues within the largest subunit of RNA polymerase II and affect transcription start site selection similarly to sua7 (TFIIB) mutations. Mol. Cell. Biol. 14: 226-237.

Blumberg, H., A. Eisen, A. Sledziewski, D. Bader, and E.T. Young. 1987. Two zinc fingers of a yeast regulatory protein shown by genetic evidence to be essential for its function. Nature 328: 443-445.

Breathnach, R. and P. Chambon. 1981. Organization and expression of eucaryotic split genes coding for proteins. Annu. Rev. Biochem. 50: 349-383.

Buratowski, S. 1994a. Yeast genetics as a tool for studying transcription initiation. In Transcription: mechanisms and regulation (ed. R.C. Conaway and J.W. Conaway), pp. 161-170. Raven Press, New York.

1994b. The basics of basal transcription by RNA polymerase II. Cell 77: 1-3.

Carles, C., I. Treich, F. Bouet, M. Riva, and A. Sentenac. 1991. Two additional common subunits, $\mathrm{ABC} 10$ alpha and $\mathrm{ABC} 10$ beta, are shared by yeast RNA polymerases. I. Biol. Chem. 266: 24092-24096.

Conaway, R.C. and J.W. Conaway. 1993. General initiation factors for RNA polymerase II. Annu. Rev. Biochem. 62: 161-
190.

Corden, J., B. Wasylyk, A. Buchwalder, C.P. Sassone, C. Kedinger, and P. Chambon. 1980. Promoter sequences of eukaryotic protein-coding genes. Science 209: 1406-14014.

Dreyfuss, G., S.A. Adam, and Y.D. Choi. 1984. Physical change in cytoplasmic messenger ribonucleoproteins in cells treated with inhibitors of mRNA transcription. Mol. Cell. Biol. 4: 415-423.

Edwards, A.M., C.M. Kane, R.A. Young, and R.D. Kornberg. 1991. Two dissociable subunits of yeast RNA polymerase II stimulate the initiation of transcription at a promoter in vitro. J. Biol. Chem. 266: 71-75.

Furter-Graves, E.M., R. Furter, and B.D. Hall. 1991. SHI, a new yeast gene affecting the spacing between TATA and transcription initiation sites. Mol. Cell. Biol. 11: 4121-4127.

Gietz, R.D. and A. Sugino. 1988. New yeast-Escherichia coli shuttle vectors constructed with in vitro mutagenized yeast genes lacking six-base pair restriction sites. Gene 74: 527-534.

Gileadi, O., W.J. Feaver, and R.D. Kornberg. 1992. Cloning of a subunit of yeast RNA polymerase II transcription factor $b$ and CTD kinase. Science 257: 1389-1392.

Guarente, L. 1987. Regulatory proteins in yeast. Annu. Rev. Genet. 21: 425-452.

-1988. UASs and enhancers: common mechanism of transcriptional activation in yeast and mammals. Cell 52: 303-305

Harrison, D.A., M.A. Mortin, and V.G. Corces. 1992. The RNA polymerase II 15-kilodalton subunit is essential for viability in Drosophila melanogaster. Mol. Cell. Biol. 12: 928-935.

Hekmatpanah, D.S. and R.A. Young. 1991. Mutations in a conserved region of RNA polymerase II influence the accuracy of mRNA start site selection. Mol. Cell. Biol. 11: 5781-5791.

Henry, N.L., M.H. Sayre, and R.D. Kornberg. 1992. Purification and characterization of yeast RNA polymerase II general initiation factor g. J. Biol. Chem. 267: 23388-23392.

Ho, S.N., H.D. Hunt, R.M. Horton, J.K. Pullen, and L.R. Pease. 1989. Site-directed mutagenesis by overlap extension using the polymerase chain reaction. Gene 77: 51-59.

Johnston, M. 1987. Genetic evidence that zinc is an essential co-factor in the DNA binding domain of GAL4 protein. $\mathrm{Na}$ ture 328: 353-355.

Johnston, M. and J. Dover. 1987. Mutations that inactivate a yeast transcriptional regulatory protein cluster in an evolutionarily conserved DNA binding domain. Proc. Natl. Acad. Sci. 84: 2401-2405.

Kolodziej, P. and R.A. Young. 1989. RNA polymerase II subunit RPB3 is an essential component of the mRNA transcription apparatus. Mol. Cell. Biol. 9: 5387-5394.

. 1991 a. Epitope tagging and protein surveillance. Methods Enzymol. 194: 508-519.

- $1991 \mathrm{~b}$. Mutations in the three largest subunits of yeast RNA polymerase II that affect enzyme assembly. Mol. Cell. Biol. 11: 4669-4678.

Li, Y., P.M. Flanagan, H. Tschochner, and R.D. Kornberg. 1994. RNA polymerase II initiation factor interactions and transcription start site selection. Science 263: 805-807.

Liao, S.M., I.C. Taylor, R.E. Kingston, and R.A. Young. 1991. RNA polymerase II carboxy-terminal domain contributes to the response to multiple acidic activators in vitro. Genes $\&$ Dev. 5: 2431-2440.

Lue, N.F., P.M. Flanagan, K. Sugimoto, and R.D. Kornberg. 1989. Initiation by yeast RNA polymerase II at the adenoviral major late promoter in vitro. Science 246: 661-664.

Lue, N.F., P.M. Flanagan, R.J. Kelleher III, A.M. Edwards, and R.D. Kornberg. 1991. RNA polymerase II transcription in vitro. Methods Enzymol. 194: 545-550. 
McKune, K. and N.A. Woychik. 1994. Functional substitution of an essential yeast RNA polymerase subunit by its highly conserved mammalian counterpart. Mol. Cell. Biol. 14: 4155-4159.

Nogi, Y., R. Yano, J. Dodd, C. Carles, and M. Nomura. 1993. Gene RRN4 in Saccharomyces cerevisiae encodes the A12.2 subunit of RNA polymerase I and is essential only at high temperatures. Mol. Cell. Biol. 13: 114-122.

Parvin, J.D. and P.A. Sharp. 1993. DNA topology and a minimal set of basal factors for transcription by RNA polymerase II. Cell 73: 533-540.

Pinto, I., D.E. Ware and M. Hampsey. 1992. The yeast SUA7 gene encodes a homolog of human transcription factor TFIIB and is required for normal start site selection in vivo. Cell 68: 977-988.

Sadhale, P.P. and N.A. Woychik. 1994. C25, an essential RNA polymerase III subunit related to the RNA polymerase II subunit RPB7. Mol. Cell. Biol. 14: 6164-6170.

Sayre, M.H., H. Tschochner, and R.D. Kornberg. 1992a. Purification and properties of Saccharomyces cerevisiae RNA polymerase II general initiation factor a. $\%$. Biol. Chem. 267: 23383-23387.

- 1992b. Reconstitution of transcription with five purified initiation factors and RNA polymerase II from Saccharomyces cerevisiae. I. Biol. Chem. 267: 23376-23382.

Schmidt, M.C., C.C. Kao, R. Pei, and A.J. Berk. 1989. Yeast TATA-box transcription factor gene. Proc. Natl. Acad. Sci. 86: 7785-7789

Struhl, K. 1987. Promoters, activator proteins, and the mechanism of transcriptional initiation in yeast. Cell 49: 295-297.

__ 1989. Molecular mechanisms of transcriptional regulation in yeast. Annu. Rev. Biochem. 58: 1051-1077.

Sweetser, D., M. Nonet, and R.A. Young. 1987. Prokaryotic and eukaryotic RNA polymerases have homologous core subunits. Proc. Natl. Acad. Sci. 84: 1192-1196.

Thompson, N.E., D.B. Aronson, and R.R. Burgess. 1990. Purification of eukaryotic RNA polymerase II by immunoaffinity chromatography. Elution of active enzyme with protein stabilizing agents from a polyol-responsive monoclonal antibody. I. Biol. Chem. 265: 7069-7077.

Treich, I., M. Riva, and A. Sentenac. 1991. Zinc-binding subunits of yeast RNA polymerases. J. Biol. Chem. 266: 2197121976.

Treich, I., C. Carles, M. Riva, and A. Sentenac. 1992. RPC10 encodes a new mini subunit shared by yeast nuclear RNA polymerases. Gene Expression 2: 31-37.

Tschochner, H., M.H. Sayre, P.M. Flanagan, W.J. Feaver, and R.D. Kornberg. 1992. Yeast RNA polymerase II initiation factor e: isolation and identification as the functional counterpart of human transcription factor IIB. Proc. Natl. Acad. Sci. 89: 11292-11296.

Tyree, C.M., C.P. George, L.M. Lira-DeVito, S.L. Wampler, M.E. Dahmus, L. Zawel, and J.T. Kadonaga. 1993. Identification of a minimal set of proteins that is sufficient for accurate initiation of transcription by RNA polymerase II. Genes \& Dev. 7: 1254-1265.

Williams, P.G. and J.G. Mason. 1985. Hybridization in the analysis of recombinant DNA. In Nucleic acid hybridization: A practical approach (ed. B.D. Hames and S.J. Higgens), pp. 139-160. IRL Press, Washington, D.C.

-Winston, F. 1992. Analysis of SPT genes: A genetic approach toward analysis of TFIID, histones, and other transcription factors of yeast. In Transcriptional regulation (ed. S.L. McKnight and K.R. Yamamoto), pp. 1271-1293. Cold Spring Harbor Laboratory Press, Cold Spring Harbor, New York.

Woychik, N.A. and R.A. Young. 1994. Exploring RNA polymer- ase II structure and function. In Transcription: Mechanisms and regulation (ed. R.C. Conaway and J.W. Conaway), pp. 227-242. Raven Press, New York.

Woychik, N.A., S.M. Liao, P.A. Kolodziej, and R.A. Young. 1990. Subunits shared by eukaryotic nuclear RNA polymerases. Genes \& Dev. 4: 313-323.

Woychik, N.A., W.S. Lane, and R.A. Young. 1991. Yeast RNA polymerase II subunit RPB9 is essential for growth at temperature extremes. I. Biol. Chem. 266: 19053-19055.

Woychik, N.A., K. McKune, W.S. Lane, and R.A. Young. 1993. Yeast RNA polymerase II subunit RPB11 is related to a subunit shared by RNA polymerase I and III. Gene Expression 3: 77-82.

Young, R.A. 1991. RNA polymerase II. Annu. Rev. Biochem. 60: $689-715$. 


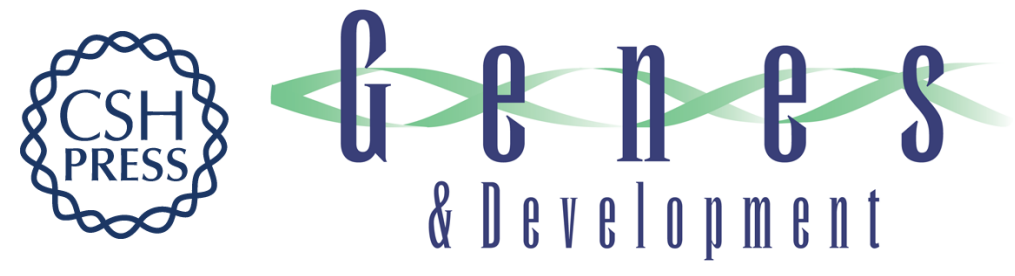

\section{RNA polymerase II subunit RPB9 is required for accurate start site selection.}

M W Hull, K McKune and N A Woychik

Genes Dev. 1995, 9:

Access the most recent version at doi:10.1101/gad.9.4.481

References This article cites 50 articles, 29 of which can be accessed free at:

http://genesdev.cshlp.org/content/9/4/481.full.html\#ref-list-1

License

Email Alerting

Service

Receive free email alerts when new articles cite this article - sign up in the box at the top right corner of the article or click here.

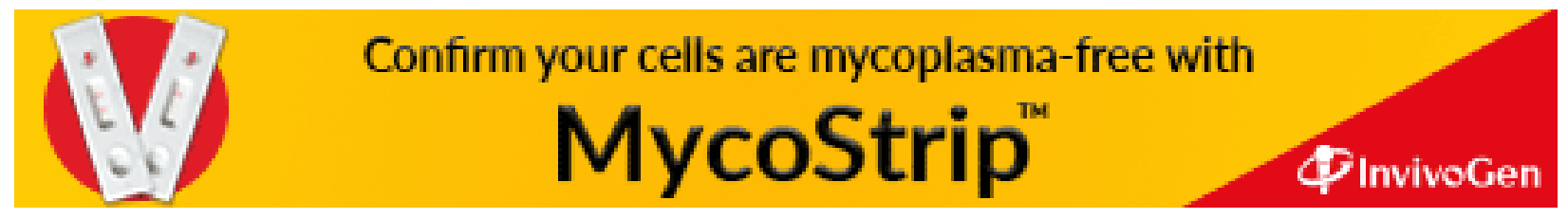

